1 Universidade Federal do Paraná (UFPR) - Curitiba (PR), Brasil.

josneidaneliu@hotmail.com

\section{A percepção dos trabalhadores sobre o processo de trabalho em um Hospital Universitário Federal sob gestão de uma empresa estatal de direito privado}

\author{
The perception of workers about the work process in a Federal \\ University Hospital under the management of a state-owned private \\ law firm
}

Josnei Luis Daneliu', Deivisson Vianna Dantas dos Santos' 1 , Sabrina Stefanello', Vitória Giacomassa de Oliveira', Guilherme Souza Cavalcanti de Albuquerque ${ }^{\mathbf{1}}$

DOI: 10.1590/0103-1104201912107

RESUMO Pesquisa com metodologia qualitativa que, a partir de entrevistas semiestruturadas, estudou o caso de um hospital universitário que passou a ser gerido por uma empresa estatal de direito privado a partir de 2014. Assim, foi possível analisar a percepção de trabalhadores de diversos setores desse serviço de saúde sobre a organização e participação no processo de trabalho de Hospital Universitário Federal (HUF) sob esse novo modelo de gestão, que se apresenta no discurso governamental como solução dos problemas de gestão dos hospitais universitários brasileiros. Os discursos dos trabalhadores, entretanto, trazem como problemas crônicos: falta de insumos, falta de flexibilidade sobre a jornada de trabalho, existência de muitos fluxos de trabalho, existência de vários níveis hierárquicos, dificuldades na interação entre trabalhadores de vínculos diferentes, inexistência de uma política de participação dos trabalhadores nos processos decisórios do hospital. Dessa forma, apenas a mudança do modelo de gestão não foi suficiente, na visão dos trabalhadores, de resolver muitos dos problemas existentes no hospital. Identificaram-se diversos elementos do paradigma empresarial-gerencialista, que está sendo colocado em prática em praticamente todos os HUF do Brasil, em que, mais do que resolver antigos problemas, acaba produzindo novos.

PALAVRAS-CHAVE Administração hospitalar. Hospitais universitários. Gestão em saúde.

ABSTRACT Research with a qualitative methodology which, based on semi-structured interviews, studied a university hospital as a case of a service that changed their model of management to a state-owned private law firm since 2014. The perception of workers was recorded and analyzed, focusing on the organization of and participation in the work process, in a Federal University Hospital (HUF) under that new model of management. The speeches brought: lack of materials, necessary to daily work, as a chronic problem; increased control over staff and lack of flexibility on work shifts; existence of many work flows; complexity of the organization chart; several hierarchical levels; difficulties in the interaction between workers with different forms of contracts; non-existence of a policy of participation of workers in the decision-making processes. Thus, only 
the change of the management model was not enough, in the view of the workers, to solve many of the Hospital's problems. Several elements of the business-managerial paradigm have been identified, which is being put into practice in practically all HUF in Brazil and, rather than solving old problems, ends up creating new ones.

KEYWORDS Hospital administration. Hospitals university. Health management.

\section{Introdução}

A implantação do Sistema Único de Saúde (SUS), após um processo de lutas e construção histórica, é uma conquista indiscutível. Em 1988, a Constituição Federal consagrou, em seu art. 196, o direito à saúde como obrigação do Estado e direito de todos. Assim, o SUS é disposto no art. 198; e suas atribuições, definidas no art. 200 da Constituição'. Na Lei nº 8.080, de 1990, o SUS é definido, como:

O conjunto de ações e serviços públicos de saúde, prestados por órgãos e instituições públicas federais, estaduais e municipais, da administração direta e indireta e das fundações mantidas pelo Poder Público2(1).

Quando os serviços de atenção à saúde forem insuficientes em determinada localidade, o SUS poderá recorrer de maneira complementar à iniciativa privada ${ }^{3}$. Porém, mesmo com o direito à saúde adquirido na Carta Magna, o processo de sua consolidação ainda enfrenta vários obstáculos: além da insuficiência de orçamento público no SUS, verificam-se problemas na gestão, principalmente em hospitais e serviços de atenção básica. A falta de profissionalização, a descontinuidade administrativa, o clientelismo e a interferência político-partidária comprometem a reputação do SUS 4 . Além disso, ao final dos seus 30 anos, o SUS ainda continua com os diversos problemas citados anteriormente, mas em um cenário no qual as políticas públicas são alvos de cortes e congelamentos em sua expansão, ${ }^{5,6}$.
Outro fator que influencia nas formas de organização do SUS ao longo de sua constituição é o avanço do projeto neoliberal no Brasil, a partir dos anos 1990, evidenciado, principalmente, pelo plano de reforma do Estado de 1995 no governo FHC (Fernando Henrique Cardoso). O plano gerou, estrategicamente, um processo de acuamento dos serviços ofertados pelo Estado, que diminuiu sua responsabilização e financiamento na área social, retirando-se taticamente do trato das mazelas sociais, transferindo esse problema para o terceiro setor e fazendo o repasse de recursos públicos para o âmbito privado ${ }^{7-9}$.

Esses fatores agregados geram grande dificuldade para definir uma forma adequada de organização do sistema se saúde. Em alguns modelos de organização, encontrados no âmbito da administração direta, que é um modelo de gestão centralizada com ação direta do Estado, as atividades devem ser desenvolvidas diretamente pela administração pública, não podendo ser delegadas a outras entidades da administração indireta. Estas últimas são compostas principalmente por alguns modelos, como as empresas públicas, autarquias, fundações de direito público e fundações estatais de direito privado. Além desses modelos, há, também, o chamado terceiro setor sob regulação estatal, constituídos pelas Organizações Sociais (OS) e Organizações da Sociedade Civil de Interesse Público (Oscip) ${ }^{\mathbf{1 0}}$.

Com o argumento de tornar a gestão mais ágil e eficiente, uma nova modalidade de gestão empresarial do SUS foi criada pela Lei ${ }^{\circ}$ 12.550/2011, denominada Empresa Brasileira 
de Serviços Hospitalares (EBSERH), pretendendo atuar de forma específica em serviços de saúde e educação. A EBSERH atua na administração de 40 Hospitais Universitários Federais (HUF) em âmbito nacional, sendo um modelo de gestão amplamente difundido e apontado pelos governantes que defenderam sua criação como a única solução para os problemas desses hospitais, a saber: falta de recursos humanos, estrutura deficiente, insuficiência de insumos, lentidão nos processos, entre outros, que desencadearam a denominada crise dos HUF ${ }^{\mathbf{1 1}, \mathbf{1 2}}$.

No Hospital de Clínicas da Universidade Federal do Paraná (UFPR), após um processo de conflitos e resistência da comunidade acadêmica, a EBSERH e a UFPR celebraram contrato de gestão em agosto de 2014.

A EBSERH é uma estrutura nova, com menos de 10 anos, que foi tida em nível nacional como a 'promessa salvadora', com um modelo jurídico de empresa posto em prática em praticamente todos os HUF do Brasil, uma vez que o formato gerencial de administração direta era e ainda é visto como a causa das dificuldades de gestão dos HUF. Portanto, esse modelo de empresa pautado pela busca de resultados, alcance de metas quantitativas, controle hierarquizado, com pouca participação dos funcionários no processo decisório das atividades de trabalho foi transportado em larga escala para área da saúde; e em hospitais escolas, que além de ofertarem complexos serviços de saúde, também formam pessoas, os denominados profissionais de saúde.

Diante do caráter inovador da EBSERH como modalidade de gestão, realizou-se a presente investigação com o objetivo de compreender a percepção de trabalhadores do Hospital de Clínicas da UFPR sobre o processo de trabalho após adesão a esse modelo de gestão.

\section{Metodologia}

Esta é uma pesquisa qualitativa, que se aprofunda no universo dos significados e das percepções dos participantes ${ }^{\mathbf{1 3}, \mathbf{1 4}}$. Ela ocorre no maior hospital público do Paraná, que possui hoje mais de 3 mil trabalhadores de diferentes vínculos jurídicos e com ações e porte explicitados na tabela 1 abaixo ${ }^{15}$.

Tabela 1. Composição do número de trabalhadores, cirurgias, internamentos e leitos do Hospital de Clínicas no período de 2010 a 2018

\begin{tabular}{|c|c|c|c|c|c|c|}
\hline \multirow[t]{2}{*}{ Dimensão para análise } & \multicolumn{4}{|c|}{ Antes da EBSERH } & \multicolumn{2}{|c|}{ Depois da EBSERH } \\
\hline & Ano & 2010 & 2011 & $2014^{\star \star}$ & 2016 & 2018 \\
\hline \multirow[t]{4}{*}{ Número de trabalhadores } & Fundação & 1.025 & 997 & 916 & 836 & 952 \\
\hline & MEC & 1.990 & 1.965 & 1.940 & 1.804 & 1.722 \\
\hline & EBSERH & - & - & - & 562 & $1.251^{\star}$ \\
\hline & Total & 3.015 & 2.962 & 2.856 & 3.202 & 3.925 \\
\hline \multirow[t]{2}{*}{ Produção } & Cirurgias & 918 (mês) & 714 (mês) & 529 (mês) & 1.080 (mês) & \\
\hline & Internamentos & 1.516 (mês) & 1.305 (mês) & 1.081 (mês) & 1.630 (mês) & \\
\hline Leitos ativos & & & & 377 & 430 & 436 \\
\hline \multicolumn{7}{|l|}{ Fonte: Elaboração própria. } \\
\hline
\end{tabular}


Nesta pesquisa, foram realizadas nove entrevistas semiestruturadas com trabalhadores - seis empregados públicos da EBSERH com vínculo da Consolidação das Leis do Trabalho (CLT) e três estatutários do Regime Jurídico Único (RJU) - de diferentes setores do Hospital de Clínicas da UFPR. A realização dos convites e a definição dos participantes da pesquisa foram feitas de forma intencional, escolhendo um profissional de diferente categoria (medicina, enfermagem, serviço social, farmacêutico) de cada uma das unidades estudadas, sendo abrangidas duas unidades de enfermaria (oncologia e neurologia), duas Unidades De Terapia Intensiva - UTI (UTI pediátrica, UTI adulto), duas unidades de apoio (farmácia e banco de sangue), uma unidade de pronto atendimento (adulto) e uma unidade ambulatorial (hematologia). Assim, tentou-se buscar uma maior pluralidade de vozes e setores. O recrutamento ocorreu via indicação de bola de neve dos próprios participantes, $o$ que facilitou a inserção de novos participantes conforme os contatos foram sendo realizados; desta forma, conseguiu-se a participação de diferentes tipos de setores com diversos processos de trabalho dentro de uma mesma instituição ${ }^{16}$. O local de realização das entrevistas ficou aberto e à escolha dos participantes da pesquisa, visando facilitar a adesão.

Para manter sigilo, os trabalhadores foram identificados com letras seguidas de números, não correspondendo à sequência de entrevistas. Os participantes deveriam ter, ao menos, um ano de trabalho no Hospital. O roteiro de entrevista contou com questões relacionadas com a organização do processo de trabalho (dia a dia), interação (com os trabalhadores que possuem outro tipo de vínculo), valorização dos trabalhadores e participação no processo de organização do trabalho. As entrevistas foram gravadas e transcritas.
Os textos foram transformados em narrativas, conforme os preceitos da hermenêutica gadameriana ${ }^{17}$, que busca o significado a partir dos fenômenos emanados dos discursos; e, a partir daí, extraíram-se os núcleos argumentais que foram agrupados em categorias construídas conforme interpretação dos discursos. Para seguir a dinâmica hermenêutica, foi feito um processo de leituras inicial superficial e detalhado das transcrições, com uma postura interpretativa que se sustenta na busca de compreensão do texto ${ }^{17}$; após, iniciou-se o processo de transformar os textos em narrativas, em que se manteve o sentido das falas originalmente criadas pelos participantes. Buscou-se, também, sintetizar os textos, enfatizando ideias repetidas. Exemplos foram apresentados de forma resumida, e os vícios de linguagem foram transformados em escrita, para tornar o texto mais corrido e compreensível, sem perder a essência das falas dos participantes. Segue-se assim o preceito hermenêutico de buscar o significado a partir dos fenômenos emanados dos discursos, extraindo-se os núcleos argumentais. Na sequência, os núcleos argumentais foram agrupados em categorias, que gerou uma grade de análise (quadro 1) que possibilitou a organização e interpretação dos discursos.

Por fim, os trabalhadores foram identificados com letras seguidas de números, com intuito de manter o anonimato, sendo os participantes com vínculo CLT representados pela letra E seguida de números de 1 a 6 , e trabalhadores estatutários RJU com a letra $\mathrm{R}$ seguida de números de 1 a 3 .

Durante a coleta de dados, foram respeitados os aspectos éticos, conforme Resolução $n^{\circ} 466 / 2012$, que trata da pesquisa com seres humanos. A pesquisa foi aprovada por Comitê de Ética em Pesquisa do Hospital de Clínicas da UFPR, parecer 2.223.897. 
Quadro 1. Grade de análise

\begin{tabular}{|c|c|c|}
\hline \multirow[t]{2}{*}{ Categorias } & Entrevista E3 - EBSERH & \multirow{2}{*}{$\begin{array}{l}\text { Núcleo } \\
\text { argumentativo }\end{array}$} \\
\hline & Trecho & \\
\hline \multirow[t]{3}{*}{$\begin{array}{l}\text { Cotidiano de } \\
\text { Trabalho }\end{array}$} & $\begin{array}{l}\text { "Em relação à flexibilidade de horário, não tem nenhuma, flexibilidade de horário é } \\
\text { sempre uma briga nossa com a chefia, porque o horário é bem engessado e bem fixo, e } \\
\text { às vezes sem muito nexo pra você entender como éfeito, mas é bem engessado. Flexibili- } \\
\text { dade não há. Essa relação, a rigidez de horário de trabalho é algo bem chato. Pra você ter } \\
\text { uma ideia, você pode ter situações, por exemplo, a minha carga horária é } 24 h \text { semanais, } \\
\text { se eu fizer } 25 \text { horas eu fico devendo horas porque não fiz exatamente no horário prees- } \\
\text { tabelecido pela minha chefia. Então, quer dizer, é algo às vezes difícil de entender e que } \\
\text { desestimula." }\end{array}$ & $\begin{array}{l}\text { Flexibilidade no } \\
\text { trabalho }\end{array}$ \\
\hline & $\begin{array}{l}\text { "Insumos... Ainda tem uma falta crônica, de, por exemplo, na minha área falta vez por } \\
\text { outra algum medicamento, a ressonância do hospital ficou fechada muito tempo, às } \\
\text { vezes falta contraste, mas faltas pontuais, mas existem. Eu gostaria de ter uma estrutura } \\
\text { melhor, por exemplo: exame de imagem demora muito tempo para sair laudo, patologia } \\
\text { também." }\end{array}$ & $\begin{array}{l}\text { Falta de insumos } \\
\text { básicos }\end{array}$ \\
\hline & $\begin{array}{l}\text { "Em relação a fluxo organizacional, o hospital é cheio de fluxos, mas em algumas áreas } \\
\text { funcionam outras áreas mais ou menos, mas existe, é bem dividido e você consegue } \\
\text { trabalhar e conhecer os fluxos sim." }\end{array}$ & $\begin{array}{l}\text { Fluxos organiza- } \\
\text { cionais }\end{array}$ \\
\hline \multirow[t]{2}{*}{$\begin{array}{l}\text { Ambiente de } \\
\text { trabalho }\end{array}$} & $\begin{array}{l}\text { "Você falou de doença com si próprio, a gente teria o ambulatório dos funcionários, } \\
\text { mas não é ambulatório para EBSERH, é pro pessoal mais da reitoria. Então a gente da } \\
\text { EBSERH, nesse ponto fica um pouco descuidado, entre aspas. A gente tem que pegar um } \\
\text { atestado e simplesmente trazer e esperar que seja aceito." }\end{array}$ & $\begin{array}{l}\text { Tratamento } \\
\text { diferenciado aos } \\
\text { trabalhadores }\end{array}$ \\
\hline & $\begin{array}{l}\text { "Bom aqui no meu setor é excelente, não tivemos problemas. Tem boatos ai, que em } \\
\text { outros setores não foi fácil, tinha muito ciúme porque é diferente a carga horária, é dife- } \\
\text { rente salário e até o regime de contratação. No hospital a gente convive com três regimes } \\
\text { diferentes, tem o pessoal da Funpar, da Reitoria e da EBSERH. Dentro do setor que traba- } \\
\text { Iho, não tem problema, mas existe setores do hospital que há realmente ciúmes e troca de } \\
\text { acusações e favorecimentos, seja por uma função ou outra." }\end{array}$ & $\begin{array}{l}\text { Interação entre } \\
\text { trabalhadores }\end{array}$ \\
\hline
\end{tabular}

Fonte: Elaboração própria.

\section{Resultados e discussão}

\section{Organização do processo de trabalho}

O processo de trabalho constitui-se pelo próprio trabalho - entendido como atividade orientada a um fim -, pelo objeto de trabalho, e pelos meios de trabalho ${ }^{\mathbf{1 8}}$.

Ayres ${ }^{19}$ coloca que, no caso dos serviços de saúde, o principal objeto sobre o qual se realiza o trabalho é o paciente, e os meios de trabalho são constituídos pelos equipamentos e materiais hospitalares utilizados para o cuidado prestado a ele. Essa relação entre os sujeitos torna o trabalho em saúde diferente de outras áreas; na saúde, existe a necessidade de inter-relação entre os trabalhadores que prestam o serviço e o usuário que consome. Para Nogueira ${ }^{20}$, esse trabalho é, portanto, essencialmente relacional, visto que existe uma necessidade do trabalhador de saúde de qualquer área profissional de interagir com seu usuário de alguma maneira. Essa interação também deve ocorrer entre os profissionais de saúde, para facilitar, promover e transformar o desenvolvimento do processo de trabalho em saúde.

Com relação à questão da qualidade e da disponibilidade dos meios de trabalho, existia uma expectativa por melhorias após a adesão à EBSERH. Na percepção de alguns trabalhadores, essa expectativa não se concretizou; e, em alguns aspectos, piorou. Essa expectativa ocorreu também no plano nacional, uma vez 
que os novos formatos de administração dos serviços públicos com instituições de direito privado, como as OS, Oscip, Fundações e a própria EBSERH, são vistos como modelos inovadores e alternativos para solucionar os problemas do considerado ultrapassado e ineficiente serviço público, que seria marcado pelo excesso de burocracia, lentidão de processos, ineficiência de resultados, falta de recursos, defasagem nos recursos humanos, na estrutura física e disponibilidade de materiais. A implantação desses modelos permitiria a fuga da fiscalização e rigidez do serviço público, com suas licitações e concursos ${ }^{21}$. Entretanto, essas faltas, que também são relatadas como um problema crônico dentro do Hospital, já existiam antes da adesão ao modelo proposto pela EBSERH e continuam a existir.

A gente esperava que melhorasse o nosso ambiente de trabalho com a entrada da EBSERH, em condições materiais, insumos, mas nada disso veio. As faltas de material e de insumos aumentaram inclusive. (R3).

Com relação à organização de trabalho, os discursos trazem que existem muitos fluxos, que estes são lentos, pouco organizados e que faltam mecanismos de controle para a fiscalização do seu bom funcionamento. Falam também que há muitos níveis hierárquicos e que o organograma é de difícil entendimento, principalmente pelo fato do excesso de cargos de coordenação. "Eu acho que são muitas chefias e você tem que passar por muitos lugares pra fazer alguma coisa" (E5).

Com relação aos horários de trabalho, é apontada reiteradamente uma falta de flexibilidade. Relatam que essa inflexibilidade com relação à jornada de trabalho é demonstrada pela difícil negociação com as coordenações. Falam também que essa rigidez na questão dos horários de trabalho prejudica o desenvolvimento das atividades.

Em relação a flexibilidade de horário, não tem nenhuma, flexibilidade de horário é sempre uma briga nossa com a chefia, porque o horário é bem engessado e bem fixo, e às vezes sem muito nexo pra você entender como é feito, mas é bem engessado. Flexibilidade não há... (E3).

Atualmente, grande parcela das instituições hospitalares se organiza pela racionalidade gerencial, que busca, por meio do planejamento, de metas, programas, definidos por um corpo diretivo superior, planejar as atividades produtivas. Para atingir essa proposta, também aposta na imposição de rígidos mecanismos disciplinares. Mecanismos de controle são implantados visando atingir metas de maneira eficiente e eficaz ${ }^{22}$. Nos discursos desta pesquisa, aparece a necessidade de ter um controle com relação ao cumprimento de horários e da jornada de trabalho, por conta do histórico de profissionais não exercendo sua carga horária no Hospital em questão. Considerando por esse prisma, os trabalhadores avaliam que a EBSERH contribuiu com eficientes mecanismos para esse controle.

Também houve um acréscimo de recursos humanos com a entrada da EBSERH no Hospital: contribuindo para sanar parte do deficit no número dos funcionários, a empresa contratou, via concurso público, 1.251 funcionários, contudo ainda não atingiu a proposta inicial que era contratar 1.775 , o que, segundo estimativas do plano de reestruturação elaborado pela EBSERH, possibilitaria colocar em funcionamento a máxima capacidade produtiva do Hospital. Nesse item, ressalva-se uma questão: por que esse deficit não começou a ser sanado antes da EBSERH? Por ser uma empresa pública, o orçamento da EBSERH é construído de aportes exclusivos da União, o que não explica por qual motivo os recursos para as contratações vieram apenas depois da transferência da gestão para a empresa.

\section{Interação no trabalho}

A entrada da EBSERH estabelece um novo marco na relação dos vínculos de trabalho dentro dos HUF, com a contratação de 
trabalhadores via concurso público no regime jurídico de empregado público regido pela CLT. O número elevado de funcionários contratados recentemente, o impacto político e a expectativa da forma de gestão da EBSERH são fatores potencialmente causadores de atritos dentro do ambiente de trabalho em saúde. Apesar de reiterados discursos não apresentarem grandes divergências na interação entre os trabalhadores, foi possível observar que essas diferenças podem suscitar atritos no ambiente de trabalho.

No interior dessa estrutura, a entrada da EBSERH gerou um choque cultural, que é apresentado por Barbosa e Costa ${ }^{23}$ como um problema na gestão das relações do trabalho em saúde, em que essas diferenças de vínculos jurídicos agregados a outros fatores das condições de trabalho afetam o relacionamento interpessoal dos profissionais. No campo de pesquisa, os discursos também apontam para esses atritos entre diferentes regimes jurídicos de contratação, tratamento diferenciado e falta isonomia, decorrentes das diferenças de vínculos de trabalho.

Outra coisa que incomoda os funcionários, não sei se são de todos os setores, mas no meu setor eu sei que existem funcionários da Reitoria que são contratados para $40 \mathrm{~h}$ e fazem 30h, e funcionários da EBSERH alguns da área assistencial têm que manter o regime de 8 h diárias, essa é uma questão que gera dúvidas qual é a razão. Na área assistencial que é a que eu trabalho não vejo razão, inclusive funcionário que no contrato recebem por $40 \mathrm{~h}$, mas trabalham $30 \mathrm{~h}$ semanais, isso é algo que incomoda bastante, a gente tem esperança que mais pra frente nosso sindicato se fortaleça e consiga ter voz com a direção para que a gente consiga criar pelo menos um meio termo nessa questão e aproximar mais a forma de trabalhar com todos os vínculos, mais pra frente conseguir uma carga horaria reduzida e legalizada. (E5).

Notou-se que existe diferença no tratamento de vários aspectos dentro do ambiente de trabalho, impactando na interação entre os trabalhadores, tanto na percepção de trabalhadores da EBSERH quanto dos da administração direta. A literatura aponta que diferentes vínculos jurídicos de trabalho inseridos em um mesmo ambiente e, às vezes, desenvolvendo a mesma atividade tendem a gerar problemas de relacionamento profissional e desenvolvimento dos serviços ${ }^{24,25}$.

\section{Participação no processo de gestão e organização do trabalho}

Reiteradamente, os discursos trazem que a voz dos trabalhadores não é ouvida, e quando existe alguma abertura para expor suas visões, estas não são levadas adiante. Os trabalhadores relatam que as decisões são centralizadas e que o cumprimento é determinado de forma verticalizada. Entretanto, apontam que essa característica organizacional não foi algo trazido pela EBSERH, mas foi algo mantido por ela.

Eu vejo que nós nunca tivemos uma política dentro do Hospital da direção vir e nos ouvir, eu vejo que a atual administradora ela é centralizadora, são coisas determinadas e não existe essa participação. (R2).

O trabalho em saúde é pautado pela inter-relação entre sujeitos. Campos ${ }^{\mathbf{2 6}}$ e Cecílio ${ }^{27}$ são adeptos a um aprofundamento da democracia institucional nos ambientes de trabalho. Eles defendem que, para a participação dos trabalhadores ser garantida, é necessária a transformação profunda no modelo de organização/gestão do trabalho das instituições, no seu organograma, com a quebra da centralização e da hierarquia dos processos; é necessária a construção de 'organogramas horizontais'.

No Hospital de Clínicas da UFPR, a matriz organizacional se assemelha, conforme as entrevistas analisadas, ao modelo gerencialista de gestão, em que os mecanismos de participação são os tradicionais descritos por Paula ${ }^{28}$. Os problemas relacionados com o processo 
participativo transparecem com discursos sobre a falta de realização de reuniões, com encontros que ocorrem eventualmente e não são divulgados com antecedência necessária. Também queixam que as opiniões e sugestões apresentadas pelos trabalhadores não são efetivadas na prática. Por fim, percebem que falta autonomia para organizar o ambiente de trabalho conforme as demandas e questões que eles se deparam no dia a dia.

A reunião de hoje era importante, mas ficamos sabendo 15 minutos antes que iria acontecer, então a gente teve uma dificuldade, não pudemos nem organizar uma pauta... (E4).

Nesse sentido, Campos ${ }^{26}$ e Matos e Pires ${ }^{29}$ colocam, também, que um sistema organizacional verticalizado, hierarquizado e com tomada centralizadora de decisões tende a estimular o descompromisso e a alienar os trabalhadores envolvidos no processo de trabalho nos serviços de saúde.

Os discursos, portanto, apontam no sentido da fragilidade da política de participação na instituição. Essa política parece nunca ter existido dentro do Hospital de Clínicas, bem como a nova administração da EBSERH não apresenta mecanismos que estimulem ou possibilitem uma efetiva participação dos trabalhadores nos processos decisórios e de organização do processo de trabalho dentro do hospital.

$\mathrm{Na}$ concepção de $\mathrm{Campos}^{30}$, para uma democracia institucional maior, é necessária a construção de um modelo de gestão participativa, com os trabalhadores inseridos na elaboração dos objetivos institucionais, participando ativamente da organização do processo de trabalho em saúde, tendo autonomia, com relações horizontais e dialógicas entre os sujeitos envolvidos. Campos ${ }^{26}$ defende que o rompimento de estruturas baseadas na divisão de departamentos com suas diferentes coordenações e normas de trabalho aumenta a adesão do trabalhador ao projeto de produção de serviços de saúde.

\section{Valorização dos trabalhadores}

Em relação à sua valorização, os trabalhadores entrevistados destacaram especialmente três aspectos: o investimento em seu aprimoramento técnico por meio da educação permanente e sua relação com a progressão funcional, o reconhecimento por parte do usuário do serviço e a relação que se estabelece entre ambos.

O processo educativo de trabalhadores da saúde é entendido como necessário, afinal, a Constituição Federal de 1988 estabelece em seu art. 200 que é de competência do SUS "ordenar a formação em recursos humanos na área da saúde"31.

Na presente pesquisa, os trabalhadores entendem a necessidade de continuar se aperfeiçoando no trabalho, corroborando a literatura, na qual a educação permanente é vista como necessária pelos trabalhadores, sendo este um processo que deve ocorrer de forma continuada, provendo sujeitos de conhecimento, articulados com experiências cientificas, acadêmicas, culturais e éticas, tornando-os capazes de aprimoramento pessoal, profissional e social, sendo esta a meta a ser seguida durante sua vida $^{32,33}$. No entanto, segundo a percepção deles, atualmente, no Hospital de Clínicas da UFPR, não há o incentivo necessário para formação e aperfeiçoamento dos profissionais.

Saída para congresso extremamente difícil, tem que preencher mil formulários 60 dias antes dependendo de onde for o congresso. Eu não sinto como um grande incentivo. Claro eu acho bom que pelo menos a possibilidade existe desde que você consiga cumprir todos os passos deste processo que é burocrático. (E1).

Os discursos trazem que, além das dificuldades para conseguir aperfeiçoamento profissional, também existe a questão de que mesmo cumprindo os requisitos para progressão, isto não é contemplado para todos os trabalhadores da EBSERH. Eles são submetidos a uma espécie de sorteio que contempla apenas alguns para alcançarem a almejada progressão, 
ou seja: mesmo cumprindo todos os passos necessários, a progressão pode não ocorrer.

[...] Por mais que você vá seguindo todas as regrinhas deles, de não ter nenhuma advertência de fazer os cursos que eles vão pedindo pra você, no final não é todo mundo que ganha a progressão. Eles fazem um sorteio, não sei exatamente como eles fazem o sorteio, mas são poucas as pessoas sorteadas. (E2).

Outros discursos trazem a valorização vinda do reconhecimento do usuário pelo serviço prestado. $\mathrm{Na}$ área da saúde, na relação entre profissional e usuário, a construção de um vínculo é fundamental para proporcionar um atendimento mais humanizado, sendo o reconhecimento dos usuários ao serviço prestado um aspecto importante nessa construção e um sinal de valorização para os trabalhadores. Esse achado coincide com o de Pinho e Santos $^{34}$ e de Cura e Rodrigues ${ }^{35}$, que afirmam que a relação com os pacientes constitui um importante fator na satisfação dos profissionais de saúde, e o reconhecimento, segundo a psicodinâmica do trabalho, está no centro da satisfação e do sofrimento no trabalho.

\section{Considerações finais}

Pôde-se observar, dessa forma, que, na percepção dos trabalhadores entrevistados, após dois anos de implantação do modelo de gestão baseado em princípios do direito privado, pouco mudou em termos de problemas cotidianos que eles vivem. São queixas crônicas, antes atribuídas ao senso comum da 'ineficiência do Estado', como falta de insumos, pouca valorização do trabalhador etc.

Ao contrário, novos problemas surgiram com adição de mais um modelo de gestão na miríade de modelos que já vigoram nos HUF. Apesar de valorizarem a maior rigidez no controle de horários que levou ao cumprimento de horários que antes parecia não existir, apontam para os problemas que essa rigidez trouxe para o trabalhador. A EBSERH entrou como mais um modelo de gestão que se sobrepõe aos outros existentes, fato corroborado pela adição de mais um formato de vínculo de trabalho ao hospital que leva a diferenças salariais, de regime, além de fomentar problemas de relacionamentos, dificuldades no relacionamento interpessoal e a formação de grupalidade.

Sobre a participação dos trabalhadores na organização do processo de trabalho, ficou evidenciado nos discursos que a voz dos trabalhadores não é ouvida e que faltam mecanismos básicos para estimular e possibilitar a participação deles. Portanto, na opinião dos entrevistados, a EBSERH adotou um modelo de gestão mais centralizador, hierarquizado e com regras rígidas, em que a voz dos trabalhadores fica em um segundo plano, e a forma de organização do processo de trabalho é imposta pelas coordenações superiores.

Que tipo de pessoas e profissionais queremos formar, dentro de uma instituição com modelo de gestão pautado por resultados, metas, com tomada centralizadora de decisões, serviços comandados por inúmeros cargos hierárquicos e com quase ou nenhuma participação dos trabalhadores no processo organizacional do trabalho? Será o modelo empresarial o melhor para a gestão dos HUF, no sentido da melhoria da qualidade dos serviços prestados de educação e saúde e do melhor uso dos recursos públicos? Longe de ser a solução mágica para os problemas dos HUF, o direito privado, principalmente neste momento de transição, convive com diversas outras dinâmicas organizacionais prévias nessas instituições, demonstrando que esse novo modelo de gestão, hoje vigente na maioria dos HUF brasileiros, deve ser mais bem estudado. Entretanto, é possível apontar que, segundo análise das percepções dos trabalhadores, esse modelo de gestão traz variados problemas na organização do dia a dia de trabalho dentro do Hospital; ademais, apenas importar ferramentas gerenciais para esse ambiente, ignorando os arranjos organizacionais tradicionais pendentes, pode ser mais uma fonte de atritos na dinâmica do trabalho em saúde. 


\section{Colaboradores}

Daneliu JL (0000-0001-9678-7618)* contribuiu substancialmente para a concepção, planejamento e para a análise e a interpretação dos dados; na elaboração do rascunho e revisão crítica do conteúdo; e aprovação da versão final do manuscrito. Santos DVD (0000-0002-1198-1890)* contribuiu substancialmente para o planejamento e para a análise e a interpretação dos dados; na revisão crítica do conteúdo; e participou da aprovação da versão final do manuscrito.
Stefanello S (0000-0002-9299-0405)* contribuiu significativamente na revisão crítica do conteúdo; e participou da aprovação da versão final do manuscrito. Oliveira VG (0000-0001-8852-552X)* contribuiu significativamente na revisão crítica do conteúdo; e participou da aprovação da versão final do manuscrito. Albuquerque GSC (0000-00027544-412X)* contribuiu substancialmente para o planejamento e para a análise e a interpretação dos dados; na revisão crítica do conteúdo; e participou da aprovação da versão final do manuscrito.

\section{Referências}

1. Santos L. SUS: desafios político-administrativos da gestão interfederativa da saúde: regionalizando a descentralização [tese]. [internet]. Campinas: Universidade Estadual de Campinas; 2012. 266 p. [acesso em 2017 set 15]. Disponível em: http://www.resbr.net.br/ wp-content/uploads/historico/SantosLenirdos_D. pdf.

2. Brasil. Lei no 8.080, de 19 de setembro de 1990. Dispõe sobre as condições para a promoção, proteção e recuperação da saúde, a organização e o funcionamento dos serviços correspondentes e dá outras providências. Diário Oficial da União. 20 Set 1990.

3. Magluta C. Políticas e sistemas de saúde no Brasil. Cad. Saúde Pública. 2013; 29(9):1912-1914.

4. Paim JS, Teixeira CF. Configuração institucional e gestão do Sistema Único de Saúde: problemas e desafios. Ciênc. Saúde Colet. 2007; 12(sup):1819-1830.
5. Paim JS. Sistema Único de Saúde (SUS) aos 30 anos. Ciênc. Saúde Colet. 2018; 23(6):1723-1728.

6. Teixeira CFS, Paim JS. A crise mundial de 2008 e o golpe do capital na política de saúde no Brasil. Saúde debate. 2018; 42(2):11-21.

7. Montaño C. Terceiro setor e questão social. São Paulo: Cortez; 2010.

8. Behring ER. Brasil em contra-reforma: desestruturação do Estado e perda de Direitos. São Paulo: Cortez; 2008.

9. Netto JP. Capitalismo monopolista e serviço social. São Paulo: Cortez; 1992.

10. Chioro A. Diferentes modelos jurídico-institucionais e a gestão hospitalar [internet]. [acesso em 2016 out 20]. Disponível em: http://www.idisa.org.br/site/ documento_1990_0_2007---diferentes-modelos-
${ }^{*}$ Orcid (Open Researcher and Contributor ID). 
-juridico-institucionais-e-a-gestao-hospitalar---arthur-chioro.html.

11. Drago LMB. "Servindo a dois senhores": a gestão do HUCAM entre o ensino e a assistência [dissertação]. [internet]. Espírito Santo: Universidade Federal do Espírito Santo; 2011. 215 p. [acesso em 2018 abr 15]. Disponível em: http://web3.ufes.br/ppgps/ sites/web3.ufes.br.ppgps/files/Leandra\%20M.\%20 Borlini\%20Drago.pdf.

12. Littike D. Improvisando a gestão por meio da gestão do improviso: o processo de trabalho dos gestores de um hospital universitário federal [dissertação]. [internet]. Vitória: Universidade Federal do Espírito Santo; 2012. 182 p. [acesso em 2016 nov 7]. Disponível em: http://portais4.ufes.br/posgrad/teses/ tese_5756_.pdf.

13. Minayo MCS, Deslandes FS, et al. Pesquisa social: teoria, método e criatividade. 28. ed. Petrópolis, RJ: Vozes; 2009.

14. Turato ER. Métodos qualitativos e quantitativos na área da saúde: definições, diferenças e seus objetos de pesquisa. Rev. saúde pública. 2005; 39(3):507-14.

15. História do Hospital de Clínicas [internet]. [acesso em 2017 maio 3]. Disponível em: http://www2.hc.ufpr. $\mathrm{br} /$ ?q=content/historia-do-hc.

16. Vinuto J. A amostragem em bola de neve na pesquisa qualitativa: um debate em aberto. Temáticas. 2014; 22(44):203-220.

17. Ricoeur P. Interpretação e ideologias. Rio de Janeiro: Francisco Alves; 1990.

18. Marx K. O Capital: crítica da economia política. São Paulo: Abril Cultural; 1983. v. I, tomo 1.

19. Ayres JRCM. Cuidado: trabalho e integração nas práticas de saúde. Rio de Janeiro: CEPESC; 2009.

20. Nogueira RP. O trabalho em serviços de saúde. In: Amâncio Filho A, Moreira MCGB, organizadores. Saúde, trabalho e formação profissional [internet].
Rio de Janeiro: Fiocruz; 1997. p. 71-76. [acesso em 2018 out 10]. Disponível em: http://books.scielo.org/ id/9tc7r/pdf/amancio-9788575412787-08.pdf.

21. Alcantara CM. Fundamentos da administração pública e novos modelos de gestão em saúde. In: Goes PSA, Moysés SJ, organizadores. Planejamento, gestão e avaliação em saúde bucal. São Paulo: Artes Médicas; 2012.

22. Vignoli VA. Flexibilização da Jornada de Trabalho: importância e limitações. [dissertação]. São Paulo: Universidade de São Paulo; 2010. 100 p.

23. Barbosa SC, Costa MTP. Condições do ambiente sociogerencial e gestão da saúde dos trabalhadores em um contexto de mudança cultural. Cad. Gestão Pública e Cidad. 2017; 22(73):437-455.

24. Bernardo MH, Pinzón JG, Verde FF. Vivências de trabalhadores com diferentes vínculos empregatícios em um laboratório público. Cad. Psicol. Soc. Trab. 2013; 16(1):119-133.

25. Alves SMP, Borges LH, Coelho MCR, et al. A flexibilização das relações de trabalho na saúde: A realidade de um Hospital Universitário Federal. Ciênc. Saúde Colet. 2015; 20(10):3043-3050.

26. Campos GWS. Equipes de referência e apoio especializado matricial: um ensaio sobre a reorganização do trabalho em saúde. Ciênc. Saúde Colet. 1999; 4(2):393-403.

27. Cecílio LCO. Autonomia versus controle dos trabalhadores: a gestão do poder no hospital. Rev. Ciênc. Saúde Colet. 1999; 4(2):315-329.

28. Paula APP. Administração pública brasileira entre o gerencialismo e a gestão social. Rev. Adm. Empres [internet]. 2005 [acesso em 2016 ago 5]; 45(1):36-49. Disponível em: http://bibliotecadigital.fgv.br/ojs/index.php/rae/article/view/37088.

29. Matos E, Pires D. Teorias administrativas e organização do trabalho: de taylor aos dias atuais, influências no setor saúde e na enfermagem. Texto e Contexto Enferm. 2006; 15(3):508-514. 
30. Campos GWS. Cogestão e neoartesanato: elementos conceituais para repensar o trabalho em saúde combinando responsabilidade e autonomia. Ciênc. Saúde Colet. 2010; 15(5):2337-2344.

31. Brasil. Constituição da República Federativa do Brasil. Brasília: Senado Federal; 1998. [acesso em 2019 jun 21]. Disponível em: https://www2.senado.leg. br/bdsf/bitstream/handle/id/518231/CF88_Livro_ EC91_2016.pdf.

32. Mantovani MF, Méier MJ, Paschoal AS. Percepção da educação permanente, continuada e em serviço para enfermeiros de um hospital de ensino. Rev Esc Enferm USP. 2007; 41(3):479-484.

33. Andrade A, Bonacina DM, Oliveira TCS, et al. Desafios na construção de um projeto de educação permanente em saúde. Rev Enferm UFSM. 2012; 2(3):496506.
34. Pinho LB, Santos SMA. O relacionamento interpessoal como instrumento de cuidado no hospital geral. Cogitare Enferm. [internet]. 2007 [acesso em 2017 maio 12]; 12(3):377-385. Disponível em: http://revistas.ufpr.br/cogitare/article/view/10038.

35. Del Cura MLA, Rodrigues ARF. Satisfação Profissional do enfermeiro. Rev. Latino-am. Enfermagem. [internet]. 1999 [acesso em 2016 abril 9]; 7(4):21-28. Disponível em: https://www.revistas.usp.br/rlae/article/view/1388.

Recebido em 27/09/2018

Aprovado em 24/01/2019

Conflito de interesses: inexistente

Suporte financeiro: não houve 